\title{
A ENCONTRABILIDADE DA INFORMAÇÃO PELO USUÁRIO NA NETFLIX BRASIL $^{1}$
}

\author{
Anésia Maria Lara ${ }^{2}$ \\ Diogo Roberto da Silva Andrade ${ }^{3}$ \\ Kevin Keler Rodrigues Ribeiro 4 \\ Larissa Pena Elguy 5 \\ Paula de Souza Ramos Pires ${ }^{6}$
}

\begin{abstract}
RESUMO
Apresenta-se um estudo da encontrabilidade das informações na Netflix Brasil. O objetivo geral é avaliar a encontrabilidade da informação pelo usuário da Netflix no Brasil em 2018. Possui como objetivos específicos analisar se as informações são fáceis de serem encontradas na Netflix Brasil. Para isso, foi realizada uma pesquisa quantitativa exploratória a partir da aplicação de um questionário survey em uma amostra de 156 pessoas que utilizam a Netflix. Foi aplicado, a partir de metodologia qualitativa, uma análise de tarefa direcionada com 6 pessoas a fim de verificar a familiaridade e as formas de encontrar a informação na plataforma. Apesar de os usuários conseguirem encontrar conteúdo para satisfazer suas necessidades de informação, a plataforma da Netflix precisa de melhorias em seus sistema de busca para otimizar a encontrabilidade da informação.
\end{abstract}

Palavras-chave: Netflix. Usuários. Encontrabilidade. Buscas de informação. Estudos de uso da web.

\footnotetext{
${ }^{1}$ Trabalho apresentado à disciplina Usuários da Informação, do curso de Biblioteconomia da Escola de Ciências da Informação da Universidade Federal de Minas Gerais, no segundo semestre de 2018, conduzida pela professora Eliane C Cristina de Freitas Rocha.

2 Discente do curso de Bibilioteconomia da Escola de Ciências da Informação da Universidade Federal de Minas Gerais - anesia_lara@uol.com.br

3 Discente do curso de Bibilioteconomia da Escola de Ciências da Informação da Universidade Federal de Minas Gerais - didtsdr@gmail.com -

${ }^{4}$ Discente do curso de Bibilioteconomia da Escola de Ciências da Informação da Universidade Federal de Minas Gerais - kevinkeler@gmail.com

${ }^{5}$ Discente do curso de Bibilioteconomia da Escola de Ciências da Informação da Universidade

Federal de Minas Gerais - larissaelguy@gmail.com

${ }^{6}$ Discente do curso de Bibilioteconomia da Escola de Ciências da Informação da Universidade

Federal de Minas Gerais - paularamospires@gmail.com
} 


\begin{abstract}
Rendering a study about human computer interaction of Netflix (in Brazil). The overall objective is to evaluate the information availability of the Netflix user in Brazil in 2018. It has the specific objectives to analyze if the information is easy to be found in streaming platform. Thereunto, the quantitative exploratory survey was carried out from the application of a survey questionnaire in a sample of 156 Netflix user. From a qualitative methodology, the task analysis with 6 people was applied to verify the familiarity and skills of finding the information in the platform. Although users are able to find content to seek information, the Netflix platform needs improvements in their search engine to optimize the findability.
\end{abstract}

Key words: Netflix. User. Human computer interaction. Information seeking. Information skills.

\title{
1 TEMA
}

A encontrabilidade da informação na Netflix Brasil. Uma noção de qualidade de diálogo entre usuário e interface.

\subsection{Revisão do tema}

Netflix e o surgimento da Internet tem transformado profundamente as janelas clássicas de distribuição de cinema, bem como a indústria da televisão ${ }^{7}$. O comportamento do assinante da plataforma é medido com frequência, a fim de se fazerem adequações em seu catálogo e atender aos requisitos técnicos do software. Pode-se afirmar que o foco da Netflix esteja em atender aos seus assinantes, a partir do conceito de encontrabilidade, assim como Vechiato e Vidotti (2014) citaram Morville (2005): a qualidade de ser localizável ou navegável e o grau no qual é facilmente descoberto ou localizado. Os comentários ajudam a rede de transmissão (plataforma ou streaming) a entender quais melhorias podem ser feitas no produto Netflix e nas ofertas de conteúdo (NETFLIX, 2018). A empresa inovou no consumo de produtos fílmicos - possui, atualmente, em seu catálogo, uma média de trinta e três mil vídeos, distribuídos entre filmes, séries, documentário, músicas/musicais, variedades, conteúdo infantil e animações -, de forma que se tornou pioneira na

\footnotetext{
${ }^{7}$ Netflix y el surgimiento de internet han [ido] transformando profundamente las ventanas clásicas de distribución del cine, así como la industria televisiva (RUIZ, 2017).
} 
disponibilidade virtual de tais produções. Despontou e foi exemplo para a nova mídia digital do mundo virtual.

Bretas (1998, p. 333) diz sobre os conceitos de televisão e vídeo e seus reflexos sociais:

\begin{abstract}
O conceito de televisão transcende às (sic) meras especificações de sua classificação como mais um eletrodoméstico. Constitui parte de um complexo institucionalizado, juntamente com outras estruturas informativas como os jornais, as revistas, o rádio etc.

A noção de vídeo é correlata à idéia (sic) de televisão, já que, entre outras aproximações, ambos se referem à tela ou ao monitor onde as imagens se definem para a recepção.
\end{abstract}

As mudanças tecnológicas que a sociedade vive intensamente afetam diretamente o volume de informação produzida. Estamos em uma época em que se prioriza o acesso às informações, por isso "os sujeitos e seus comportamentos, competências e habilidades passam a ter importância necessária e esperada para 0 projeto de sistemas e ambientes informacionais" (VECHIATO; VIDOTTI, 2014, p. 46). Os usuários, para bom aproveitamento de toda a informação possível, devem, portanto, ser ao menos familiares com os sistemas oferecidos. Santana e outros autores (2016, p. 88) citam Robredo (2003, p. 109) quanto à importância do acesso e de tal familiaridade, quando comentam que "o acesso deve acontecer de forma cada vez mais rápida", e que "os sistemas de informação têm se tornado importantes em todos os setores produtivos". Incluem-se as fontes fílmicas (televisivas, documentárias, cinematográficas, etc) tanto para entretenimento como para conhecimento e material de pesquisa.

Para elucidar a relação do usuário com tais sistemas, podem-se estudar caminhos de que se lança mão para encontrar as ditas fontes e delas usufruir. Assim se toma Santana e outros autores (2016, p. 89), quando citam Morville e Callender (2010): "a encontrabilidade se refere à visibilidade da informação, a possibilidade de encontrá-la e localizá-la, as ações de pesquisa e busca e encontrar objetos e respostas e (re)encontrar páginas, pessoas, lugares e produtos".

A Netflix possui sistemas de busca direta, por meio da caixa de texto (Figura 1) presente em todo tipo de navegação. Ela está em quaisquer eletrônicos de onde se possa acessar o sistema. Nela se podem pesquisar: títulos de filmes, séries e afins; gente, diretores, artistas, entre outros membros de produção, elenco e equipe; gêneros das produções fílmicas em geral. 
Figura 1 - Busca direta Netflix Brasil.

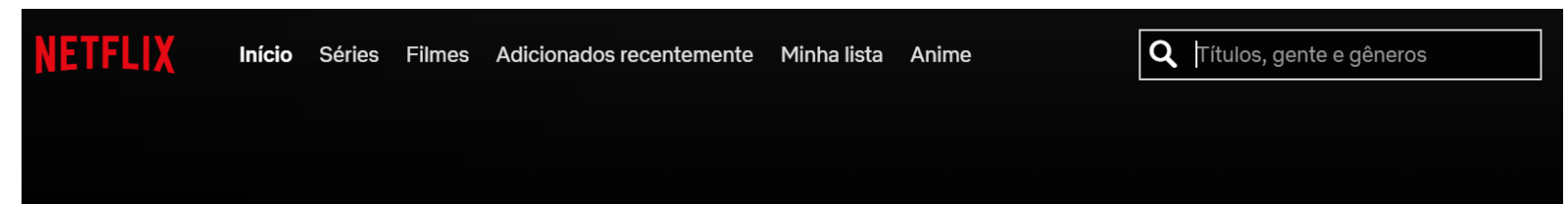

Fonte: adaptado de NETFLIX, 2018.

Outra forma de pesquisa se dá pela busca indireta. Kalbach (2007) nos diz que "a disponibilidade imediata de recursos adicionais permite que as pessoas modifiquem suas estratégias de busca rapidamente". Tal acesso se faz também presente na Netflix por meio de seu mosaico interativo (Figura 2), organizado por temas e gêneros fílmicos presentes na tela inicial. Dentro dos subtemas "séries" e "filmes", o streaming oferta catálogos de gêneros (Figura 3 e 4).

Figura 2 - Painel interativo Netflix Brasil.

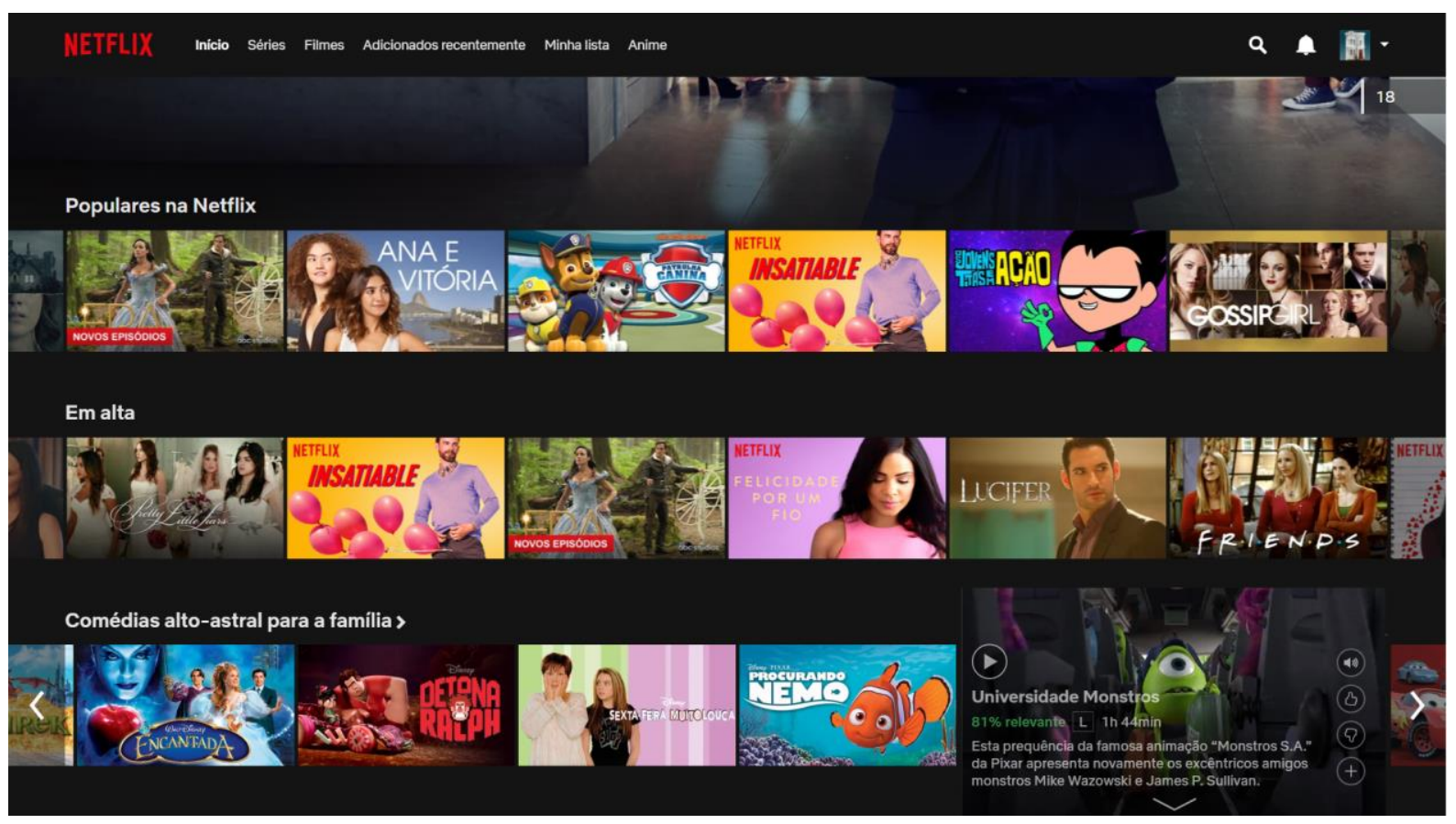

Fonte: adaptado de NETFLIX, 2018 
Figura 3 - Séries e opções de gêneros.

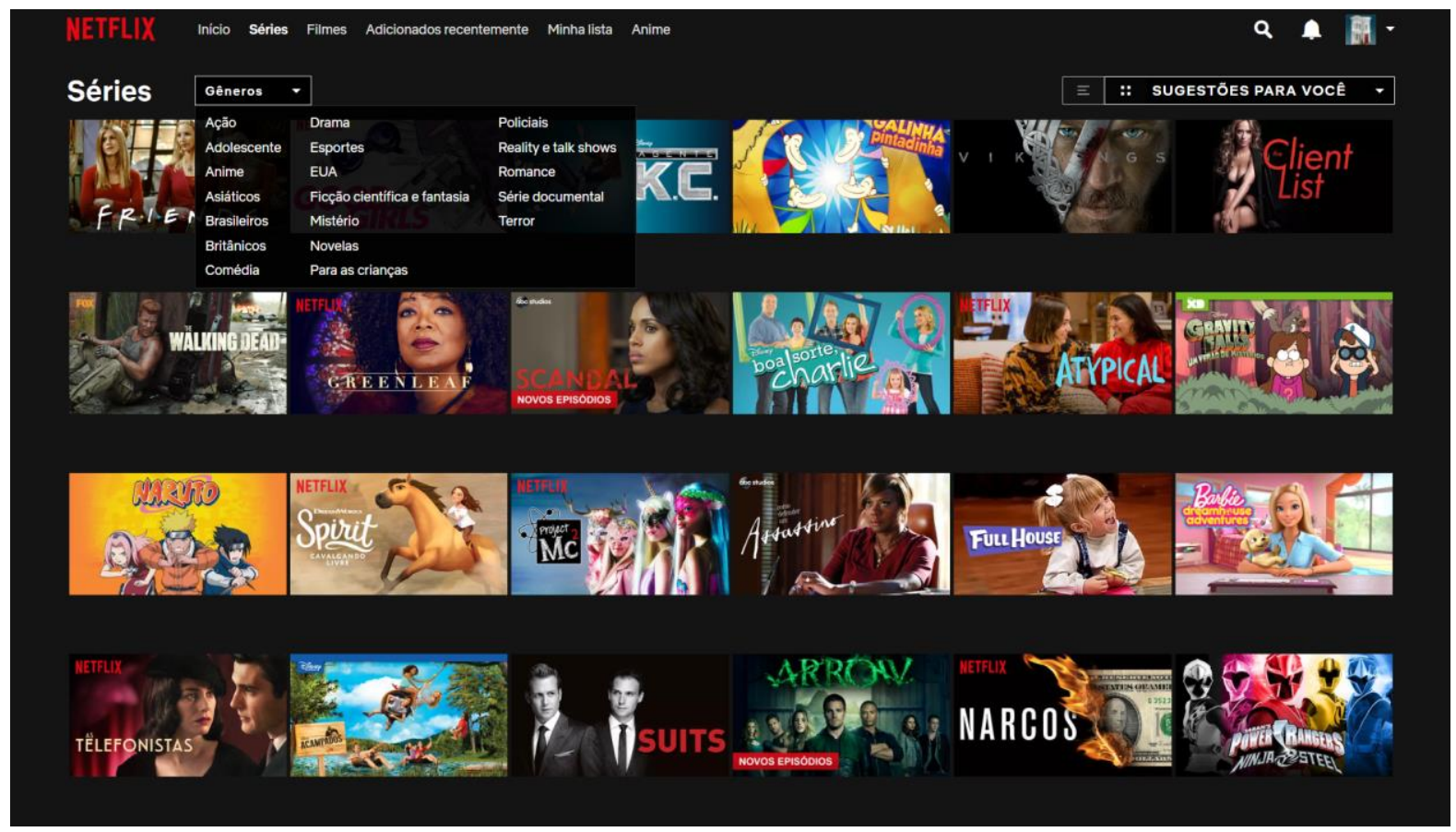

Fonte: adaptado de NETFLIX, 2018.

Figura 4 - Filmes e opções de gêneros.

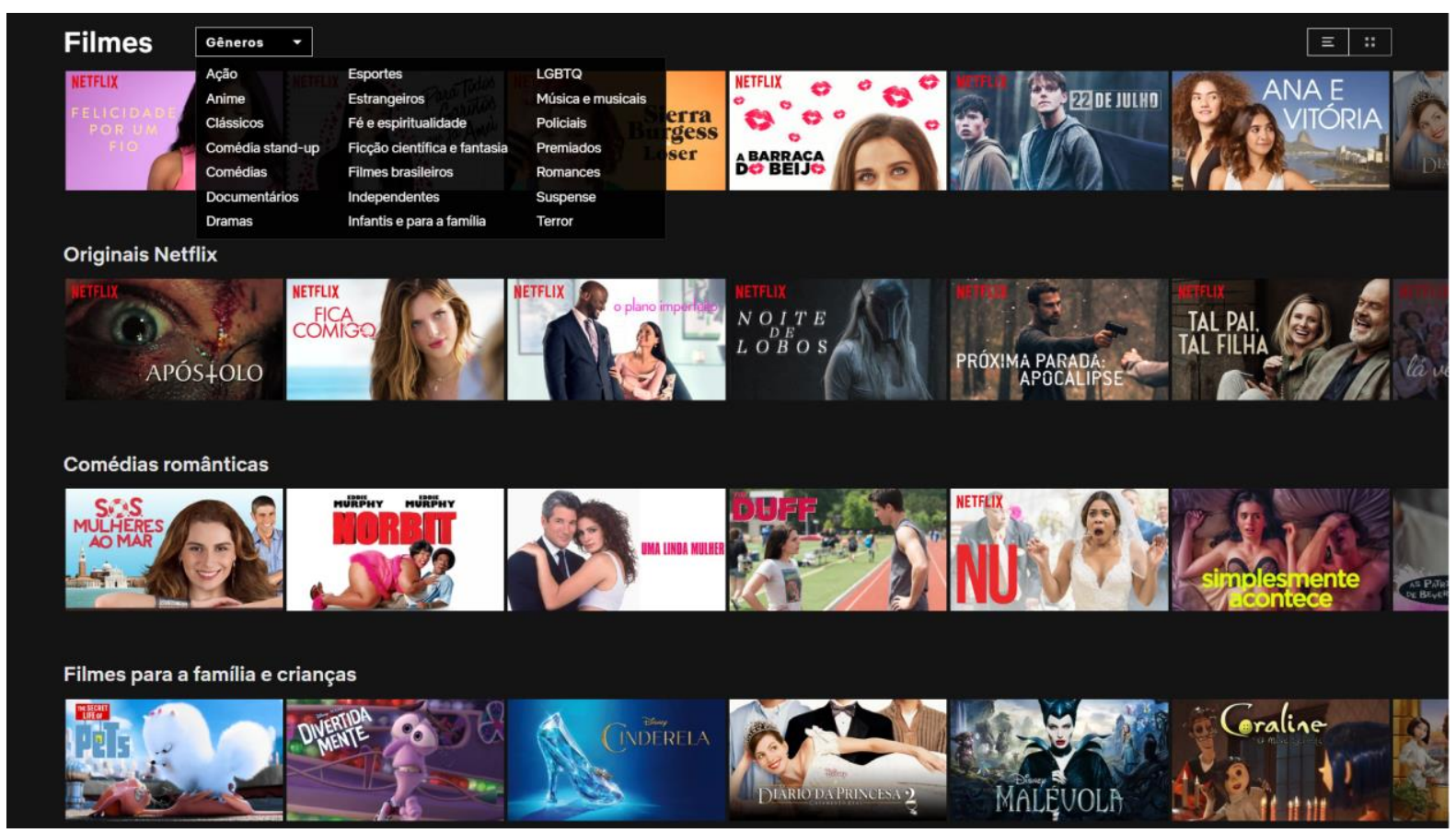

Fonte: adaptado de NETFLIX, 2018.

Observa-se que as múltiplas opções de busca e navegação estão presentes simultaneamente. Dessa forma, há uma relação com as etapas de busca, pois o desenvolvedor precisa estar atento a cada uma delas para projetar navegação que 
dê suporte ao sujeito durante a busca, em suas variadas formas de procura por informação.

\section{DEFINIÇÃO DO PROBLEMA}

Atualmente a Netflix, rede de transmissão online para conteúdo audiovisual, é reconhecida pela sua enorme gama de conteúdo (filmes, séries, documentários, animações, programas de entretenimento, reality show, musicais etc). Estando disponível em mais de 190 países, a rede de transmissão busca atender a todos os usuários e suas especificações. O catálogo ativo conta com produções originais, bem como disponibiliza, por período de tempo indefinidos, conteúdos de outras marcas e produtoras. Tem como objetivo atender a todos os públicos, de todos os níveis, nichos e faixas etárias.

$\mathrm{O}$ acesso à rede Netflix é essencialmente virtual. Pode ser realizado por meio de eletrônicos online, como televisores (Smart TV), computadores, notebooks, videogames, dispositivo de streaming de conteúdo (Chromecast, Amazon Fire Stick, Apple TV, DVD/Blu-ray player), decodificadores, smartphones ou tablets. É necessário acesso à internet e compatibilidade com o software.

A busca por conteúdo tende a ser simplificada e auto-induzível. No painel interativo, o usuário encontra opções de busca dos títulos por meio de um sistema simplificado, assim pode pesquisar pelo título da obra, gênero, elenco, diretor, temas e afins, como indicado pela Netflix busca por: "títulos", "gente", "gêneros".

O estudo de usuário tem o intuito de saber se as formas de pesquisa e a oferta de conteúdo atendem às necessidades de busca do usuário de forma prática. Diante do exposto, foi levantada a seguinte problemática: os usuários conseguem encontrar as informações para suprir suas necessidades de entretenimento na Netflix?

\section{OBJETIVO}

Os objetivos a seguir foram usados como parâmetros para a pesquisa que foi desenvolvida. 


\subsection{Objetivo Geral}

Avaliar a encontrabilidade da informação pelo usuário da Netflix no Brasil em 2018.

\subsection{Objetivos Específicos}

- Analisar se as informações são fáceis de serem encontradas na Netflix Brasil.

- Analisar qual tipo de aparelho é utilizado para acessar o serviço da Netflix.

- Analisar as facilidades e dificuldades de busca e navegação pelo usuário da Netflix Brasil.

\section{PESQUISA QUANTITATIVA}

Quanto aos fins, é uma pesquisa exploratória, pois, de acordo com Gonçalves (2005, p. 56), é quando "se encontra na fase preliminar, possibilitando sua definição e delineamento". Uma vez que se pretende descrever características da encontrabilidade da informação Netflix, apresentadas pelos usuários, é também descritiva. Segundo Gil (2002, p. 42), tem "como objetivo primordial a descrição das características de determinada população ou fenômeno ou, então, o estabelecimento de relações entre variáveis".

\subsection{Definição da amostragem}

O universo "é a agregação teórica e hipotética de todos os elementos definidos num survey" (BABBIE, 1999, p. 121). O universo corresponde a 7.500.000 assinantes da Netflix no Brasil, de acordo com divulgação da empresa. Apesar de a Netflix possuir atuação internacional, adotou-se o recorte geográfico com foco no Brasil, a fim de identificar os usuários assinantes por conveniência.

Assim, foi adotada amostragem não-probabilística acidental, que é obtida "pelos casos que vão aparecendo, que são possíveis, até que a amostra atinja determinado tamanho" (BARROS, LEHFELD, 2000, p. 41).

De acordo com margem de erro amostral de $8 \%$ e confiança de 95\%, deverão ser aplicados 151 questionários, com base na população de 7.500.000. Para Freitas 
et al. (2000, p. 107), "as chances de obtenção de valores ou resultados alinhados com a realidade aumentam consideravelmente com 100 observações".

\subsection{Definição das técnicas de coleta de dados e dos instrumentos de coleta}

O método de pesquisa adotado foi o survey, que busca obter dados para caracterizar e descrever informações quantitativas de uma população-alvo, conforme aponta Freitas et al. (2000). A pesquisa survey pode ser interseccional, que diz respeito à coleta de dados de uma população em um intervalo de dias (BABBIE, 1999). Pinsonneault e Kraemer (1993), citados por Freitas et al. (2000, p. 106), apontam que a pesquisa survey descritiva busca verificar se "a percepção dos fatos está ou não de acordo com a realidade".

O questionário estruturado que consta no Apêndice $A$ foi utilizado como instrumento de coleta de dados, por meio da divulgação do link de hospedagem via Google forms. Foi realizada online, por e-mail e nas redes sociais, a fim de se contemplarem acidentalmente pessoas que fossem assinantes da Netflix no Brasil.

\subsection{Coleta de dados}

Os dados de pesquisa quantitativa foram coletados na forma de questionário. Primeiramente aplicou-se pré-teste online (Apêndice A), contendo 12 questões, com objetivo de averiguar o entendimento dos respondentes quanto à capacidade de compreensão dos enunciados, assim como das respostas ofertadas. A partir deste, feitas alterações necessárias, enviamos questionários online (Apêndice B), por meio de uma plataforma eletrônica virtual, chamada Google Forms ${ }^{\mathrm{TM}}$.

O acesso aos questionários se iniciou em 28 de setembro de 2018, por meio da plataforma online, e esteve aberto a todo e qualquer participante. A quantidade de 156 questionários - em acordo com o item "definição de amostragem" - foi alcançada em 5 de outubro de 2018. O envio do questionário se deu por meio de email, de publicações em redes sociais e de mensagens em aplicativos de mensagens instantâneas. Os dados coletados foram tratados no programa Office Excel ${ }^{\circledR}$. 


\subsection{Tratamento e análise dos dados coletados}

Com os dados obtidos da pesquisa, pode ser identificado o perfil dos pesquisados, conforme consta no Gráfico 1. Ao cruzar os dados de sexo e idade, é observada a predominância de $32 \%$ do público feminino na faixa etária de 18 a 24 anos, $11 \%$ do público masculino e $1 \%$ que preferiu não dizer. Na faixa etária de 25 a 34 anos, conta-se com $18 \%$ do público feminino e $19 \%$ do masculino, e, na faixa dos 35 a 44 anos, são $7 \%$ do público masculino e $5 \%$ do feminino.

Gráfico 1 - Gráfico por Sexo e Idade

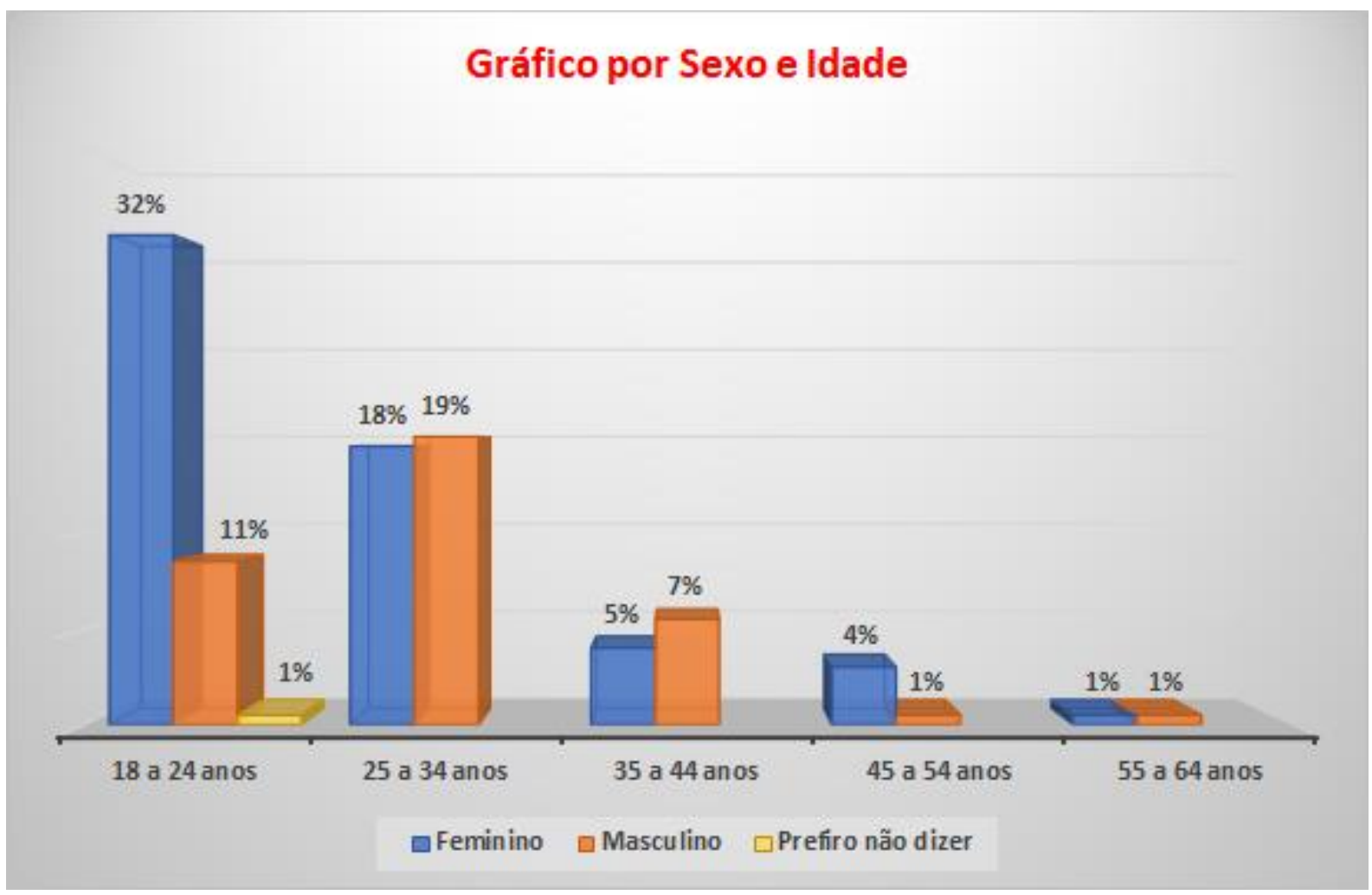

Fonte: Dados da Pesquisa, 2018.

No gráfico 2, verifica-se a preferência de utilização por três aparelhos: Computador (29\%), TV $(29 \%)$ e Celular $(28 \%)$. Aparelhos de videogames foram citados, corresponderam a $8 \%$ e os tablets com $6 \%$. Uma vez que, para acessar a Netflix, é necessário estar conectado à internet para usufruir da programação, os dados apresentados corroboram com a expectativa de que os três aparelhos mais mencionados fossem as formas mais populares de acesso. 
Gráfico 2 - Gráfico de Uso por Aparelho

\section{Gráfico de Uso por Aparelho}

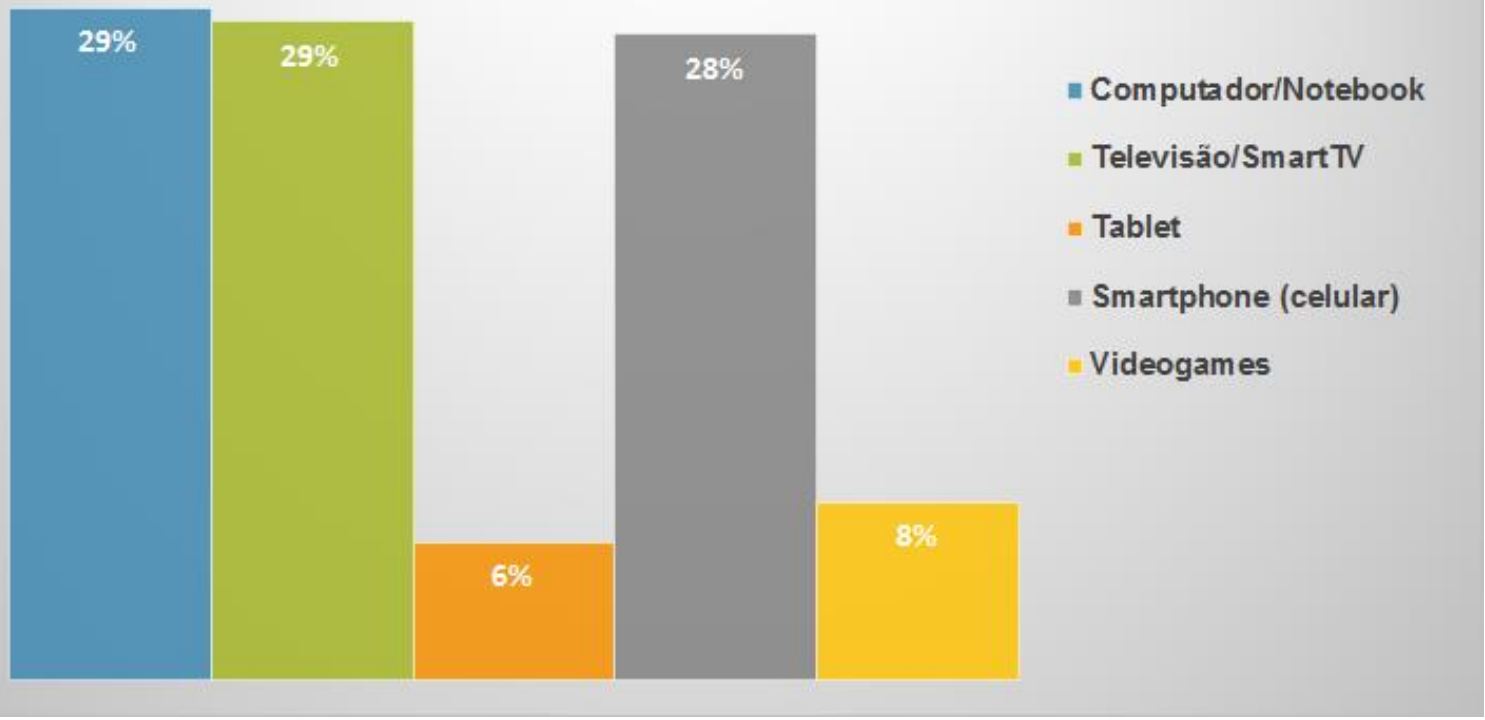

Fonte: Dados da Pesquisa, 2018.

No Gráfico 3, a faixa etária de 18 a 24 anos apresenta maior facilidade (30\%) de utilizar a Netflix pelo computador e notebook. Essa faixa etária corresponde à geração de nativos digitais, por isso manusear os aparelhos em questão talvez seja realmente mais fácil para eles. Na faixa etária de 45 a 54 anos, 25\% consideram fácil utilizar pelo celular; $14 \%$ de 35 a 44 anos consideram o tablet; $22 \%$ de 25 a 34 anos consideram a televisão de fácil uso. 
Gráfico 3 - Gráfico Grau de Facilidade por Aparelho e Faixa Etária

\section{Gráfico Grau de Facilidade por Aparelho e Faixa Etária}

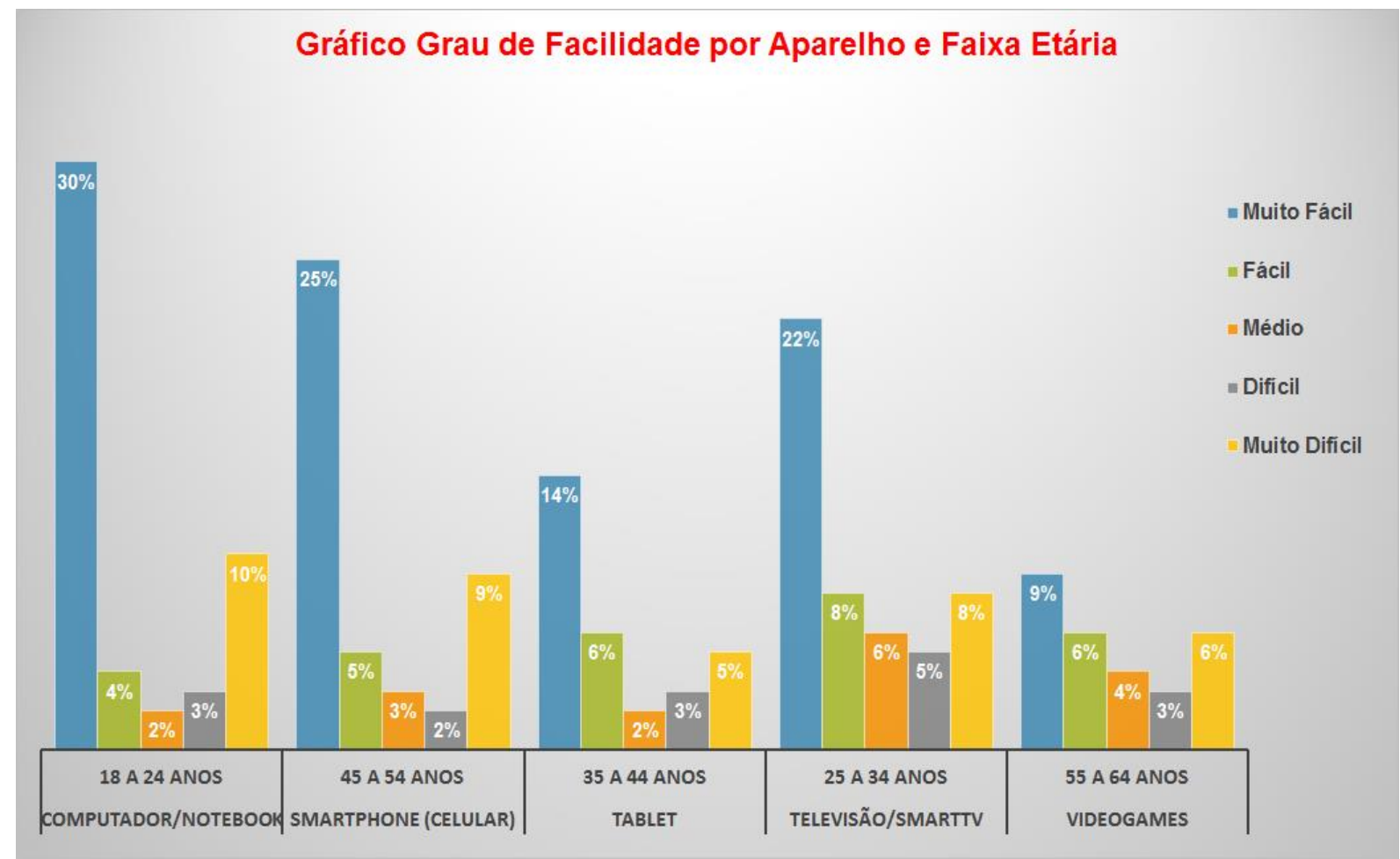

Fonte: Dados da Pesquisa, 2018.

Tabela 1 - Tabela de Frequências

\begin{tabular}{|c|c|c|c|c|c|}
\hline \multicolumn{5}{|c|}{ Frequência Absoluta } \\
\hline Grau de Facilidade por Aparelho & Muito Fácil & Fácil & Médio & Dificil & Muito Dificil \\
\hline Computador/Notebook & 76 & 10 & 5 & 8 & 24 \\
\hline Televisão/SmartTV & 55 & 20 & 15 & 12 & 19 \\
\hline Tablet & 34 & 16 & 5 & 8 & 13 \\
\hline Smartphone (celular) & 64 & 12 & 7 & 6 & 22 \\
\hline Videogames & 22 & 14 & 11 & 7 & 16 \\
\hline Total & 251 & 72 & 43 & 41 & 94 \\
\hline \multicolumn{7}{|c|}{ Frequência Relativa } \\
\hline Grau de Facilidade por Aparelho & Muito Fácil & Fácil & Médio & Dificil & Muito Dificil \\
\hline Computador/Notebook & $30 \%$ & $4 \%$ & $2 \%$ & $3 \%$ & $10 \%$ \\
\hline Televisão/SmartTV & $22 \%$ & $8 \%$ & $6 \%$ & $5 \%$ & $8 \%$ \\
\hline Tablet & $14 \%$ & $6 \%$ & $2 \%$ & $3 \%$ & $5 \%$ \\
\hline Smartphone (celular) & $25 \%$ & $5 \%$ & $3 \%$ & $2 \%$ & $9 \%$ \\
\hline Videogames & $9 \%$ & $6 \%$ & $4 \%$ & $3 \%$ & $6 \%$ \\
\hline
\end{tabular}

Fonte: Dados da Pesquisa, 2018.

Os assinantes informaram a preferência sobre o conteúdo a que assistem no serviço. No Gráfico 4, são perceptíveis os principais tipos de conteúdo, os mais acessados são Séries (38\%) e Filmes (32\%) . Os menos utilizados são: Variedades, 
Infantis e Musicais, com 3\% cada. A disponibilidade da Netflix parece ter atraído o antigo público dos cinemas enquanto espaço físico de exibição de filmes. Pode-se notar, também, que as séries ganham espaço na predileção dos assinantes e usuários pelo uso do streaming. Isso talvez se associe bastante à mobilidade dos entretenimentos, ou seja, não se precisar mais sair de casa para ver na telona dos memoráveis cinematógrafos.

\section{Gráfico 4 - A que Prefere Assistir}

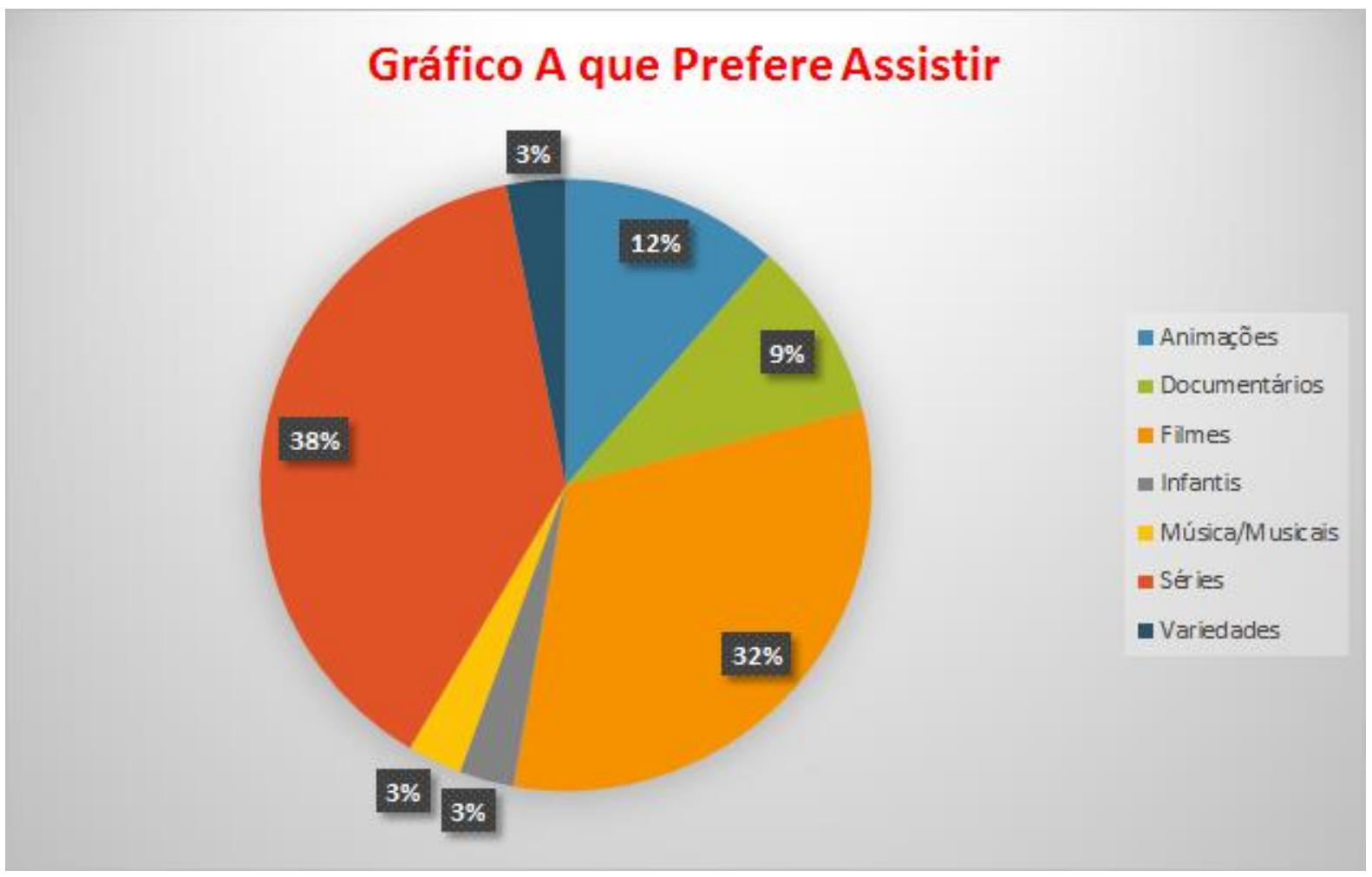

Fonte: Dados da Pesquisa, 2018.

Para identificar o problema que foi estabelecido na pesquisa, foi questionado aos respondentes se conseguem encontrar a informação na Netflix. No Gráfico 5 é observado que $87 \%$ afirma que consegue encontrar o que deseja. 
Gráfico 5 - Gráfico de encontrabilidade da informação

\section{Gráfico Ao fazer a busca, Você Encontra o que Deseja?}

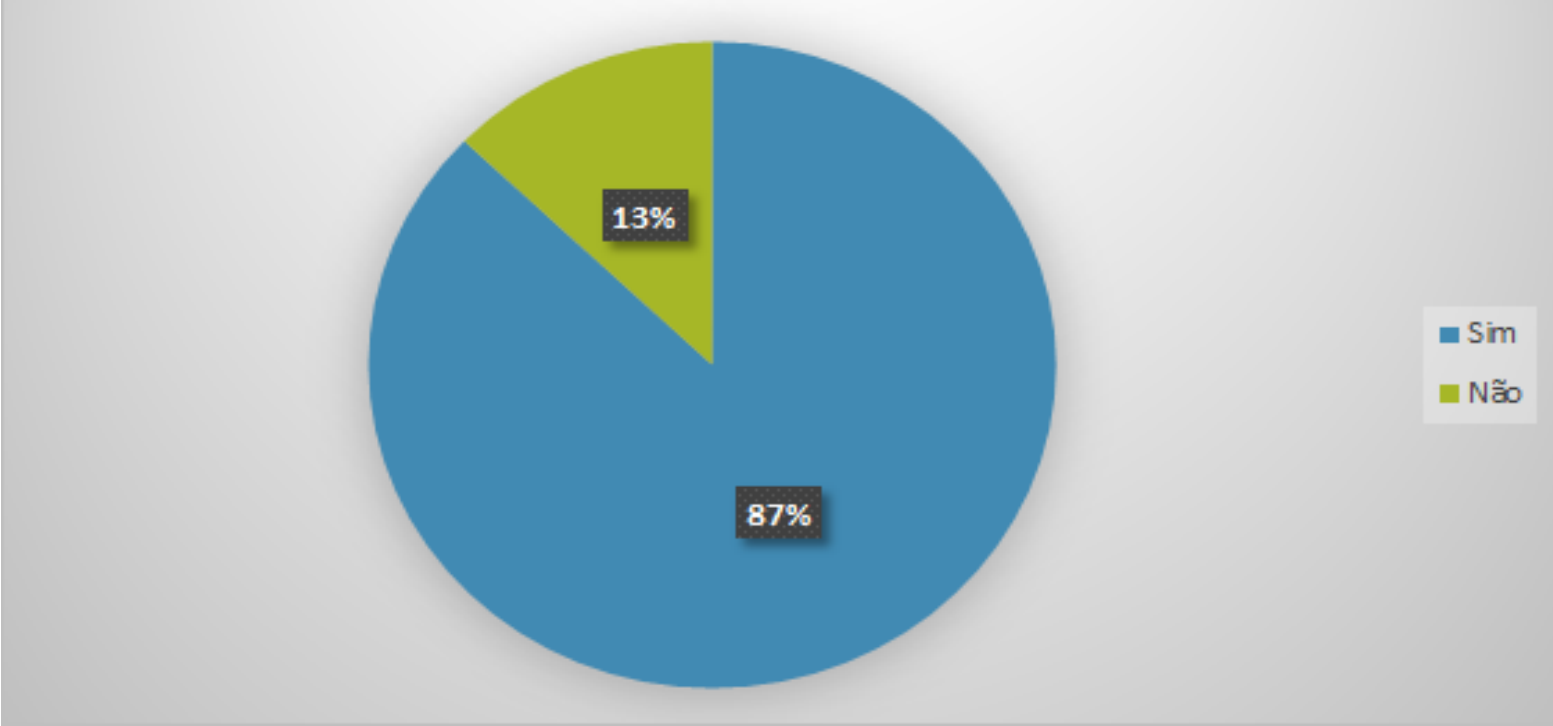

Fonte: Dados da Pesquisa, 2018.

No Gráfico 6, fica evidenciado que grande parte dos assinantes consideram muito fácil realizar uma pesquisa no serviço, apenas os respondentes de 55 a 64 anos informam ser médio o grau de facilidade. Os respondentes de 18 a 24 anos e 35 a 44 anos tiveram a mesma porcentagem em relação a grau de facilidade, ambos consideram muito fácil realizar uma pesquisa. Parte dos entrevistados de 35 a 44 anos $(7 \%)$ consideram muito difícil a pesquisa por título, enquanto os respondentes de 55 a 64 anos (9\%) consideram médio a pesquisa por Diretor(es). 
Gráfico 6 - Gráfico de Grau de Facilidade de Pesquisa por Faixa Etária

Gráfico Grau de Facilidade de Pesquisa por Faixa Etária

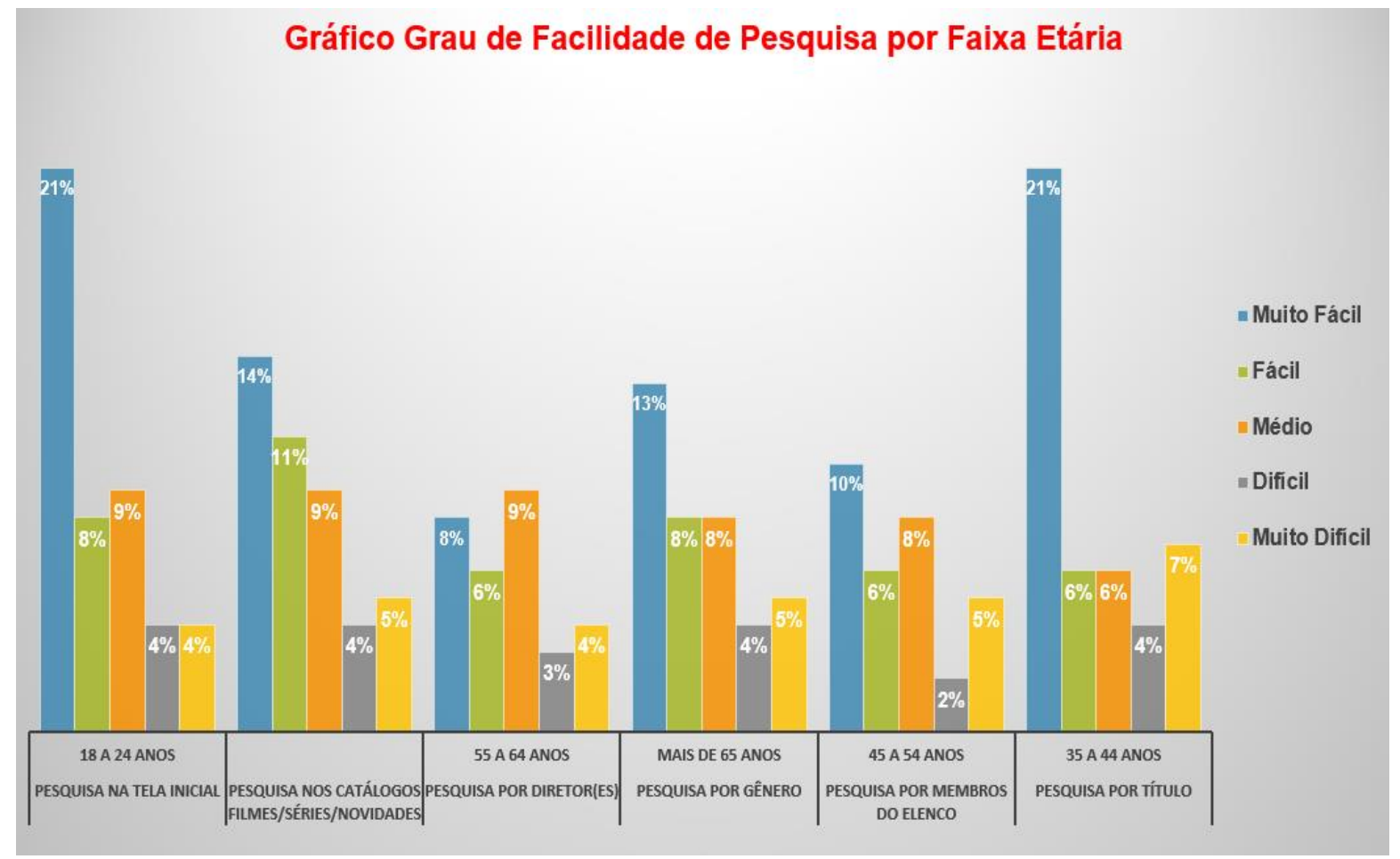

Fonte: Dados da Pesquisa, 2018.

Tabela 2 - Tabela de Frequências

\begin{tabular}{|c|c|c|c|c|c|}
\hline \multicolumn{7}{|c|}{ Frequência Absoluta } \\
\hline Grau de Facilidade da Encontrabilidade & Muito Fácil & Fácil & Médio & Difícil & Muito Dificil \\
\hline Pesquisa na tela inicial & 67 & 26 & 28 & 14 & 14 \\
\hline Pesquisa nos catálogos (filmes/ séries / novidades) & 46 & 36 & 30 & 14 & 15 \\
\hline Pesquisa por título & 67 & 20 & 21 & 13 & 24 \\
\hline Pesquisa por membros do elenco & 32 & 21 & 27 & 8 & 15 \\
\hline Pesquisa por diretore(s) & 26 & 19 & 28 & 10 & 14 \\
\hline Pesquisa por gênero & 41 & 25 & 25 & 13 & 17 \\
\hline Cria uma lista de preferidos & 46 & 12 & 18 & 12 & 14 \\
\hline Total & 325 & 159 & 177 & 84 & 113 \\
\hline \multicolumn{7}{|c|}{ Frequência Relativa } \\
\hline Grau de Facilidade da Encontrabilidade & Muito Fácil & Fácil & Médio & Difícil & Muito Dificil \\
\hline Pesquisa na tela inicial & $21 \%$ & $8 \%$ & $9 \%$ & $4 \%$ & $4 \%$ \\
\hline Pesquisa nos catálogos (filmes/séries/novidades) & $14 \%$ & $11 \%$ & $9 \%$ & $4 \%$ & $5 \%$ \\
\hline Pesquisa por título & $21 \%$ & $6 \%$ & $6 \%$ & $4 \%$ & $7 \%$ \\
\hline Pesquisa por membros do elenco & $10 \%$ & $6 \%$ & $8 \%$ & $2 \%$ & $5 \%$ \\
\hline Pesquisa por diretor(es) & $8 \%$ & $6 \%$ & $9 \%$ & $3 \%$ & $4 \%$ \\
\hline Pesquisa por gênero & $13 \%$ & $8 \%$ & $8 \%$ & $4 \%$ & $5 \%$ \\
\hline
\end{tabular}

Fonte: Dados da Pesquisa, 2018. 


\subsection{Elaboração de conclusões sobre o problema investigado quantitativamente}

Diante dos dados apresentados, conclui-se que grande parte dos assinantes da Netflix conseguem localizar o que desejam. Alguns possuem dificuldades na forma como localizam a informação, mas a maioria sente facilidade na forma preferencial de busca de informação no serviço da Netflix. O público feminino predomina em relação ao número de assinantes, com $44 \%$ do total dos respondentes. Os aparelhos mais utilizados para acessar o serviço são: Computador, TV e Celular, com $29 \%$ nos dois primeiros e $28 \%$ no último. A maioria dos entrevistados considera muito fácil a utilização dos aparelhos para acessar o serviço, em todas as idades. Os respondentes relataram, em sua maioria, que, ao buscar o conteúdo a que desejam assistir, conseguem localizar aquilo que procuram, com $87 \%$ das respostas positivas. Uma pesquisa qualitativa crítica será apresentada no próximo item, para analisar alguns aspectos mais profundos sobre a encontrabilidade dos assinantes no serviço Netflix.

\section{PESQUISA QUALITATIVA}

pesquisa qualitativa não se preocupa com representações numéricas. Tem como finalidade a compreensão de uma realidade social. Trata de aspectos que possuem uma gama de significados profundos. Como apontam Gerhardt e Silveira (2009, p. 32), esse tipo de pesquisa apresenta características de

objetivação do fenômeno; hierarquização das ações de descrever, compreender, explicar, precisão das relações entre o global e o local em determinado fenômeno; observância das diferenças entre o mundo social e o mundo natural [...].

\subsection{Definição da amostragem}

A amostra qualitativa toma como preferência sujeitos que possuem atributos representativos da relação com o assunto pesquisado e, dessa maneira, podem contribuir para a investigação, como aponta Gonçalves (2005). 
Para essa etapa da pesquisa, foi adotada amostra não-probabilística intencional, que, para Barros e Lehfeld (2000, p. 42), é aquela em que "o pesquisador se dirige intencionalmente a grupos de elementos dos quais deseja saber a opinião". Sendo assim, foram selecionadas 6 pessoas para coleta de dados sobre a dificuldade da encontrabilidade de informações na Netflix.

\subsection{Definição das técnicas de coleta de dados e dos instrumentos de coleta}

Técnica de coleta dos dados foi a entrevista qualitativa, pois busca explorar dados que não foram relatados na técnica quantitativa. A fim de atender aos objetivos da pesquisa, foram delineados alguns temas que estão relacionados aos objetivos propostos. Para Fraser e Gondim (2004, p.145):

\footnotetext{
É prática comum a elaboração de um roteiro apresentado sob a forma de tópicos (tópico-guia) que oriente a condução da entrevista, mas que de modo algum impeça o aprofundamento de aspectos que possam ser relevantes ao entendimento do objeto ou do tema em estudo.
}

Como instrumento de coleta foi utilizados, portanto, uma grade de análise de tarefas e a observação orientada (Apêndice $\mathrm{C}$ ), por meio dos quais os pesquisadores observavam e norteavam os entrevistados, a fim de conseguir coletar os dados necessários que qualificassem os objetivos da pesquisa.

\subsection{Coleta de dados}

Os dados da pesquisa qualitativa, aplicada em forma de análise de tarefa, foram coletados primeiramente na forma de pré-teste em dois usuários, na data de 8 de novembro de 2018, seguindo a grade de análise de tarefas com base no roteiro elaborado pelo grupo. O pré-teste foi realizado com o intuito de verificar a familiaridade, facilidade e desempenho das questões elaboradas, e se isso agregaria valor ao propósito da pesquisa.

Não foram necessárias alterações nas tarefas elaboradas pelo grupo de pesquisadores. Por conseguinte, na mesma data em que foram aplicados os prétestes, foi feita a observação de tarefa com 6 usuários que se denominam ativos do streaming (Netflix) e se voluntariaram a serem observados e filmados enquanto orientados a seguir os passos da tarefa. A escolha, da maioria dos entrevistados, foi 
baseada nos dados quantitativos, segundo os quais a maioria dos usuários são mulheres, jovens (entre 18 e 24 anos), que utilizam computador/notebook para acessar a Netflix.

As filmagens foram analisadas e transcritas pelos pesquisadores, utilizando a suíte de aplicativos da Microsoft ${ }^{\mathrm{TM}}$ (Office Word ${ }^{\circledR}$, Media Player $^{\circledR}$ e Office Exce $^{\circledR}$ ).

\subsection{Tratamento e análise dos dados coletados}

Realizou-se a análise de tarefa de seis entrevistados por meio de um roteiro orientado de buscas. Os usuários 1, 2, 3 e 4 são do sexo feminino, da faixa de 18 a 24 anos. O usuário 5 é também do sexo feminino, da faixa etária de 35 a 44 anos. Por fim, usuário 6 , do sexo masculino, da faixa etária de 18 a 24 anos.

A entrevistada 1 teve grande facilidade em buscar por "conteúdo" e por "série". Escolheu prontamente uma programação frente ao "conteúdo" que a Netflix Ihe ofereceu, no mosaico inicial. Na aba "séries" também, de forma que revelou ter hábito de usar a rede com frequência. Na aba "filmes", abriu o submenu de "gênero" e passeou por ele com familiaridade. Explorou cerca de cinco das programações, relanceou as sinopses e fez a escolha.

Na busca direta por "gente", digitou no espaço da lupa (busca direta) o diretor "Tim Burton", para o qual apareceram vários de seus filmes e ainda sugestões relacionadas, o que agradou a entrevistada. Na busca direta por "títulos", ela digitou uma série e foi informada de que não constava no catálogo naquele momento. $\mathrm{O}$ orientador da tarefa questionou se a entrevistada sabia que tal série não estava na Netflix. Ela respondeu que já esteve. Ao que parece, ela estava conferindo se havia retornado.

A entrevistada 2, objetivamente na página inicial, fez a escolha de uma "série", sem mais delongas no painel interativo da tela inicial da Netflix, ainda que o orientador informasse que poderia rolar pra baixo, pra cima, pra direita, pra esquerda. Diferente de, ao ser solicitado para buscar na aba "séries", e entrar no submenu "gênero", ter procurado por tempo relativamente maior, de forma que ficou passeando pelas opções pra cima, pra baixo, pra direita, por quase dois minutos. Pareceu estar fazendo uma procura primorosa, já que tinha à frente tantas opções.

$\mathrm{Na}$ tarefa de busca direta por "personalidades", no campo a ser preenchido "Título, gente, gêneros", o usuário escreveu "Robert Downei Jr.", mas não obteve 
resposta. Na verdade, procurava por "Robert Downey Jr.", como se pode observar na Figura 6. Acreditava estar escrevendo certo, daí desistiu por não se lembrar a forma correta, mesmo que soubesse haver conteúdo desse artista no catálogo. Se Ihe fosse mostrado "opção de autocompletar", provavelmente o usuário ficaria satisfeito. Em contrapartida, ao escrever o nome de uma série, digitou corretamente em primeira mão e ficou feliz de ter encontrado de imediato.

Figura 6 - Busca direta: gente.

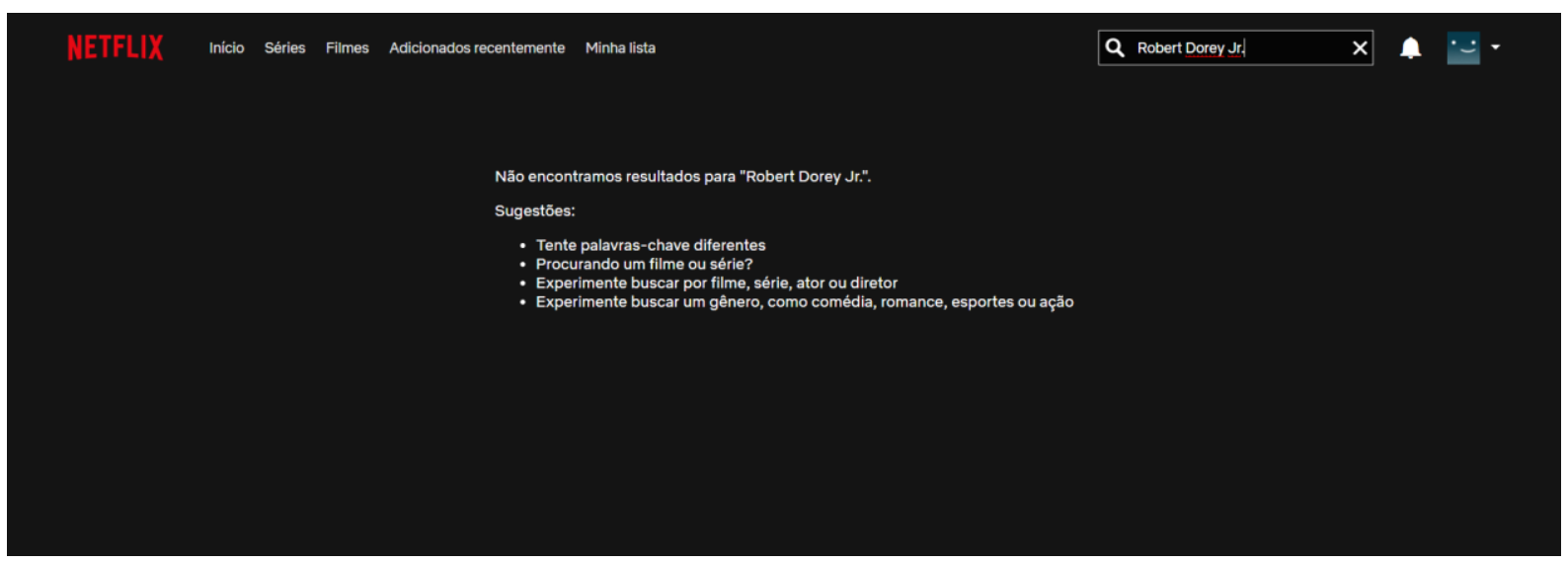

Fonte: adaptado de NETFLIX, 2018.

A entrevistada 3 se familiarizou rapidamente com a tela inicial, de forma a utilizar as barras de rolagem para observar quais conteúdos estavam disponíveis. Na primeira tarefa, foi escolhido um conteúdo que já se apresentava na tela inicial, a série "O mundo sombrio de Sabrina", que é conteúdo original recém-lançado.

Na busca por "séries", quanto ao "gênero", foi escolhido "adolescente". A entrevistada observou a tela de rolagem e percebeu que havia nela uma subdivisão de conteúdos. Nessa etapa da tarefa, a entrevistada também optou por escolher um conteúdo que se apresentava na tela inicial, escolhendo a série "Elite". Na pesquisa de "filme" por "gênero", foi escolhido "comédia". A entrevistada observou a tela inicial, percorreu toda a barra de rolagem e por fim escolheu o filme "Plano Imperfeito", que também estava em destaque como "conteúdos originais" da Netflix.

Na busca direta por "gente", começou a digitar "Zoey De", logo a plataforma sugeriu o nome "Zoey Deutch" na opção "veja títulos sobre". Na busca direta por "filme", a entrevistada pesquisou por "Vingadores" e a Netflix indicou todos os filmes relacionados aos "Vingadores". Foi observado que a entrevistada possui facilidade ao realizar as tarefas e tem preferência por assistir a conteúdos que são indicados 
na tela inicial pela Netflix.

A entrevistada 4 teve dificuldade em se familiarizar com a tela inicial, pois não sabia como funcionava a disposição do conteúdo. Por isso, a caixa de pesquisa que tem o símbolo da lupa para fazer pesquisa direta foi o primeiro ícone que chamou a atenção. Na primeira tarefa, foi escolhida a série "Friends", que estava na aba das "séries populares".

$\mathrm{Na}$ tarefa de busca de "série" por "gênero", foi escolhido "comédia", e, na tela inicial, selecionada a série "Orange is the new black". Na busca por "filme", foi escolhido o "gênero" de "filmes clássicos" e o "Star Wars" foi indicado pela Netflix, que apareceu na tela inicial e foi a escolha da entrevistada. Na busca direta por "gente", a palavra de busca foi "Beyoncé", enquanto na busca por "filme" foi pesquisado "Dreamgirls: em busca de um sonho".

A entrevistada 5 operou com facilidade o computador/notebook, porém deixou clara a preferência pelo uso do tablet. Inicialmente mostrou desconforto ao utilizar a versão site da Netflix, por estar acostumada com o app para periféricos eletrônicos portáteis. De qualquer forma, conhecia os recursos de busca, barras de rolagem e painéis interativos do streaming.

Na busca direta por "gente", buscou por "Song Hye-kyo". Fez a entrada por parte do nome da atriz, digitando "Song Hye", então esperou o algoritmo oferecer sugestões de produções fílmicas de seu catálogo, porém a Netflix alertou que não havia "conteúdo" referente à atriz que foi pesquisada no catálogo. Daí o sistema sugeriu produções similares, como se observa na Figura 5. 
Figura 5 - Busca direta: gente.

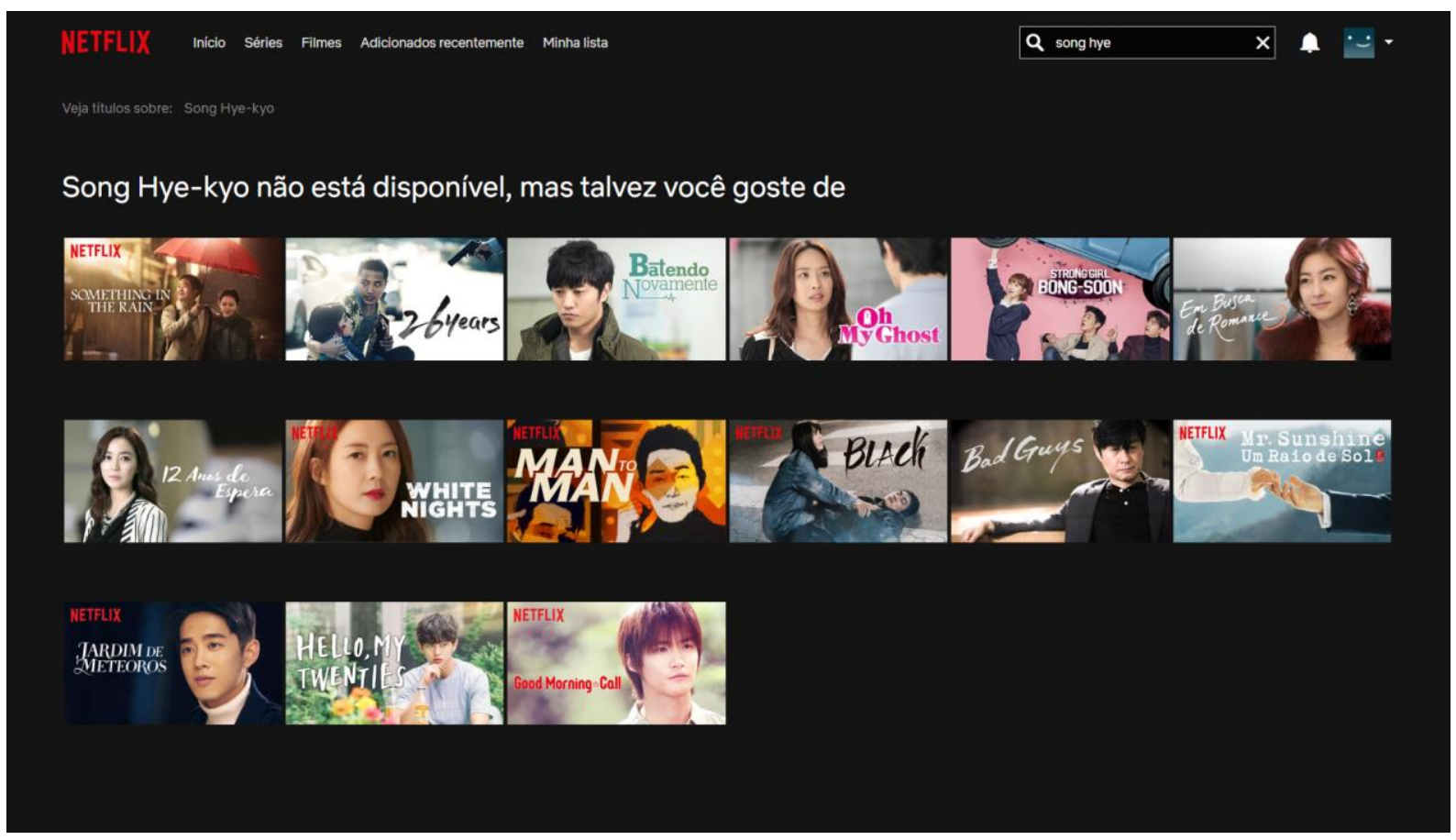

Fonte: adaptado de NETFLIX, 2018.

Na sequência de tarefas, buscou por "gêneros" o termo "K-drama" (dramas coreanos) e escolheu um dos títulos ofertados pelo painel interativo. A entrevistada, em sua busca, manifestou frustração no primeiro momento, no entanto acabou por escolher, dentre as opções oferecidas, uma produção que lhe chamasse atenção ou despertasse curiosidade.

O entrevistado 6 teve grande facilidade e dinamismo nas tarefas propostas ao manusear o computador/notebook e ao utilizar a plataforma. Conhecia as ferramentas de busca da Netflix assim como suas barras de rolagem e painéis interativos.

Na busca direta, por "gente", procurou pela atriz "Scarlett Johansson", sem erros de grafia. Dessa forma, o algoritmo imediatamente recuperou a entrada. $\mathrm{Na}$ busca direta por "títulos", buscou uma mesma série que havia escolhido anteriormente durante a tarefa de busca indireta por "séries" dentro de "gêneros", a produção da Netflix "Castlevania". 


\subsection{Elaboração de conclusões sobre o problema investigado qualitativamente}

Foi observado que a Netflix, por meio de suas múltiplas formas de busca e pesquisa, constantemente indica conteúdos próprios, acima dos outros conteúdos, para seus clientes. Essa é uma forma de marketing que vem sendo reconhecida por atrair novos apreciadores de produções fílmicas. Os usuários sempre serão direcionados a produções que os possa agradar, e, assim, de forma sutil, sempre assistir a algo antes de desligar seu aparelho.

Com o constante aperfeiçoamento das tecnologias de informação, a utilização de smartphones e outros portáteis eletrônicos tem tomado campo dos aparelhos de televisão e dos computadores/notebook. Alguns participantes da análise de tarefa tiveram dificuldade para se adaptar ao uso das funções da Netflix no computador/notebook, mas observaram ao longo das tarefas que o streaming segue um padrão auto-induzível para todos os periféricos.

Analisou-se também o algoritmo de busca direta, por meio da caixa de pesquisa do streaming. Diferente de outros produtos da World Wide Web, o buscador analisado não possui o recurso "correção de termos" ou "autocompletar", o que acaba por comprometer a busca feita pelos usuários por barreiras de linguagem - uma das dificuldades comuns aos usuários.

Dos usuários observados e analisados, uma ocorrência merece destaque. Durante a busca direta feita pelos entrevistados, é recorrente o sistema induzir passivamente algum conteúdo produzido e/ou de distribuição exclusiva pela Netflix, baseando-se em conteúdo similar ao pesquisado.

Desta feita, pode-se perceber que, com base nas pesquisas, os usuários conseguem, de certa forma, encontrar as informações para suprir suas necessidades de entretenimento na Netflix. A plataforma não consegue, contudo, suprir todas as ocorrências em suas formas e opções de busca no aparelho eletrônico testado pelos pesquisadores.

\section{CONSIDERAÇÕES FINAIS}

Após extensa jornada de pesquisas com levantamento de dados, desenvolveram-se conclusões, passíveis de inferências, sobre a encontrabilidade da informação pelo usuário da Netflix em território brasileiro, de modo a focar em 
navegação no site do streaming: as facilidades e as dificuldades de busca pelo usuário no sistema por meio do eletrônico mais utilizado.

Os resultados quantitativos foram, de certa forma, ao encontro do que era previsto, ao passo que os qualitativos despertaram a atenção para nuances do momento de busca, principalmente para as opções de escolha diante de encontrar realmente o que se pretendia ou se dirigir para opções oferecidas no momento da busca.

\subsection{Considerações gerais sobre os resultados}

Vê-se, neste trabalho, a relação existente entre os usuários da Netflix no Brasil e suas facilidades ou dificuldades para utilizarem uma busca no catálogo do streaming, como eles preferem buscar aquilo que desejam e inclusive os aparelhos preferidos, em relação à idade do usuário, o que, de certa maneira, teve uma participação expressiva para os resultados quantitativos. Observou-se como isso influencia a maneira de utilização do serviço de streaming.

Alguns possuem dificuldades na maneira como localizam a informação, mas, por meio dos resultados, percebeu-se que a maioria sente facilidade na forma preferencial de busca de informação no serviço da Netflix. O público feminino predomina em relação ao número de assinantes e os aparelhos mais utilizados para acessar o serviço são: Computador, TV e Celular. Os resultados da pesquisa quantitativa foram intuitivos para a elaboração, a compreensão e para uma análise mais profunda da etapa qualitativa.

$\mathrm{Na}$ etapa qualitativa, constatou-se que a interação com os aparelhos eletrônicos e a busca é muito particular. Apesar de a plataforma possuir as mesmas estratégias de buscas nos diferentes aparelhos, fica a critério do usuário como lidar com a informação fornecida pela plataforma.

Seria interessante, para análises futuras, segmentar a pesquisa para usuários da Netflix, por exemplo, quanto ao tempo ou as vezes em que acessou o sistema, e, a partir daí, promoverem-se análises quanto ao grau de facilidade em relação ao domínio da ferramenta. Isso, talvez, provocaria uma discussão em torno de um uso intuitivo do que a plataforma proporciona e outro uso mais afinado diante do que o usuário já tenha explorado. 


\subsection{Conclusões sobre o problema investigado}

Diante da problemática levantada neste trabalho, que consistiu em investigar se os usuários conseguem encontrar as informações para suprir suas necessidades de entretenimento na Netflix, conclui-se que, de modo geral, os usuários conseguem encontrar as informações. Existe, no entanto, o envolvimento de uma série de aspectos que influenciam na busca, como o próprio usuário que sofre influência dos aspectos cognitivos de acordo com cada faixa etária.

O sistema apresenta alguns truncamentos enquanto dispositivo de pesquisa, quando não completa ou não corrige uma palavra digitada de acordo com os dados que já se encontram no catálogo. Ao digitar uma palavra errada, mesmo que exista o que está sendo pesquisado no catálogo, a plataforma não recupera a busca. Esse é um dos fatores, que foi identificado a partir da análise de tarefa, que pode dificultar a encontrabilidade da informação na Netflix. Além disso, quando uma palavra não é recuperada, não há uma mensagem a indicar para o usuário que o produto não faz parte do catálogo, o que gera dúvidas para o usuário que não sabe se fez a pesquisa errada, se o streaming não opera corretamente ou se realmente não existe o conteúdo no catálogo.

A Netflix possui uma série de algoritmos que influenciam o usuário na encontrabilidade, principalmente no que diz respeito a produções próprias. Quando o usuário faz uma busca, a plataforma sempre indica produções próprias mesmo que não haja relação direta com o conteúdo pesquisado. Ocorre a parada problemática, uma vez que o usuário, quando não encontra o que deseja, escolhe outro conteúdo que pode ser semelhante a sua busca inicial. Cabe destacar que tais aspectos relacionados ao algoritmo independe do tipo de aparelho eletrônico que está sendo utilizado para o acesso à plataforma de streaming.

Considera-se, portanto, que, apesar de ser possível encontrar conteúdo para satisfazer as necessidades de entretenimento, como se observou na pesquisa quantitativa, o sistema da Netflix, de uma forma geral, necessita de melhorias para que as informações sejam encontradas. A partir da pesquisa qualitativa, por análise de tarefas, percebeu-se ser necessário implantar vários formatos de busca que possam contemplar os usuários da plataforma que possuem níveis de entendimento tecnológico diversificados. 


\section{REFERÊNCIAS}

BABBIE, E. Métodos de Pesquisas de Survey. Tradução Guilherme Cezarino. Belo Horizonte: Ed. UFMG, 1999, 519 p.

BARROS, A. J. P. de; LEHFELD, N. A. de. Projeto de pesquisa: propostas metodológicas. 4. ed. Petrópolis: Vozes, 2000, 102 p.

BRETAS, M. B. A. S. Televisão e vídeo. In: CAMPELLO, Bernadete Santos; CALDEIRA, Paulo da Terra; MACEDO, Vera Amália Amarante (Org.). Formas e expressões do conhecimento: introdução às fontes de informação. Belo Horizonte: Escola de Biblioteconomia da UFMG, 1998. 414 p.

FRASER, M. T. D.; GONDIM, S. M. G. Da fala do outro ao texto negociado: discussões sobre a entrevista na pesquisa qualitativa. Paidéia, v. 14 n. 28, p. 139 152, 2004. Disponível em:

<http://www.scielo.br/scielo.php?script=sci_arttext\&pid=S0103-

863X2004000200004>. Acesso em: 20 out. 2018.

FREITAS, $\mathrm{H}$. et al. O método de pesquisa survey. Revista de Administração, São Paulo, v. 35, n. 3, p. 105-112, julho/setembro, 2000. Disponível em: $<$ http://www.clam.org.br/bibliotecadigital/uploads/publicacoes/1138_1861_freitashenr iquerausp.pdf>. Acesso em: 14 set. 2018.

GERHARDT, T. E.; SILVEIRA, D. T. Métodos de pesquisa. Coord. Universidade Aberta do Brasil - UAB/UFRGS e pelo Curso de Graduação Tecnológica Planejamento e Gestão para o Desenvolvimento Rural da SEAD/UFRGS. - Porto Alegre: Editora da UFRGS, 2009.

GIL, A. C. Como elaborar projetos de pesquisa. 4. ed. - São Paulo:Atlas, 2002

GONÇALVES, H. de A. Manual de metodologia de pesquisa científica. São Paulo: Avercamp, 2005.

HASSENZAHL, M. User experience (UX): towards an experiential perspective on product quality. In: CONFERENCE ON L'INTERACTION HOMME-MACHINE, 20, 2008. Homme-Machine. Anais... ACM, New York, 2008. Disponível em:

$<$ https://issuu.com/hassenzahl/docs/towards_experiental_perspective $>$. Acesso em: 14 set. 2018.

KALBACH, J. Entendendo a navegação. In: KALBACH, J. Design de navegação Web. Porto Alegre: Bookman, 2007. cap. 2, p. 44-75.

NETFLIX. Pesquisas com clientes da Netflix. Disponível em: <https://help.netflix.com/pt/node/48042> Acesso em: 14 set. 2018.

SANTANA, C. A. et al. Comparando métodos de avaliações de usabilidade, de encontrabilidade e experiência do usuário. Informação \& Tecnologia (ITEC), João Pessoa, v. 3, n. 1, p. 83-101, jan./jun. 2016. Disponível em:

<http://www.periodicos.ufpb.br/ojs/index.php/itec/article/view/38411>. Acesso em: 14 
set. 2018.

RUIZ, V. H. Revolución Netflix: desafíos para la industria audiovisual. Chasqui Revista Latinoamericana de Comunicación, Equador, v. 1, n. 135, p. 275-295, ago./nov., 2017. Disponível em:

<http://www.revistachasqui.org/index.php/chasqui/article/view/2776>. Acesso em: 14 set. 2018.

VECHIATO, F. L.; VIDOTTI, S. A. B. G. Encontrabilidade da informação: atributos e recomendações para ambientes informacionais digitais. Informação \& Tecnologia (ITEC), João Pessoa, v. 1, n. 2, p. 42-58, jul./dez. 2014. Disponível em: <http://basessibi.c3sl.ufpr.br/brapci/_repositorio/2015/12/pdf_22269d886d_00000163 43.pdf>. Acesso em: 02 out. 2018. 


\section{APÊNDICES}

Apêndice A - Questionário pré-teste

1- Você é brasileiro? ( ) Sim - ( ) Não (se não, encerrar o questionário)

2- Você é assinante da Netflix? ( ) Sim - ( ) Não (se não, encerrar o questionário)

3- Qual seu sexo? ( ) Feminino - ( ) Masculino - ( ) Outro - ( ) Prefere não declarar

4- Indique sua faixa etária: ( ) 18 a 24 anos - ( ) 25 a 34 anos - ( ) 35 a 44 anos ( ) 45 a 54 anos - ( ) 55 a 64 anos - ( ) mais de 65 anos

5- Há quanto tempo é assinante Netflix? ( ) Há 2 meses - ( ) Entre 3 meses e 8 meses - ( ) Há um ano - ( ) Mais de um ano

6- De onde costuma acessar a Netflix? ( ) Computador/Notebook - ( ) Televisão Smart TV - ( ) Tablet - ( ) Smartphone (celular) - ( ) Videogames - ( ) outras formas de acesso eletrônico (pode marcar mais de uma opção)

\section{7- Qual aparelho você prefere utilizar, para acessar a Netflix?}

( ) Computador/Notebook - ( ) Televisão Smart TV - ( ) Tablet - ( ) Smartphone (celular) - ( ) Videogames - ( ) outras formas de acesso eletrônico (pode marcar mais de uma opção)

8- De acordo com a resposta anterior, caso tenha marcado mais de uma opção: use a escala de 1 a 5 , sendo 1 muito fácil e 5 muito difícil.

Qual o grau de facilidade você encontra em cada aparelho eletrônico?

1( ) 2 ( ) 3 ( ) 4 ( ) 5 ( ) Computador/Notebook

1( ) 2 ( ) 3 ( ) 4 ( ) 5 ( ) Televisão Smart TV

1( ) 2 ( ) 3 ( ) 4 ( ) 5 ( ) Tablet

1( ) 2 ( ) 3 ( ) 4 ( ) 5 ( ) Smartphone (celular)

1( ) 2( ) 3( ) 4( ) 5( ) Videogames 
9- Ao acessar a Netflix, você: ( ) sempre procura o que quer assistir - ( ) assiste ao que é sugerido pelo catálogo - ( ) assiste à indicação feita por amigos - ( ) outros (pode marcar mais de uma opção)

10- A que você prefere assistir? ( ) Filmes - ( ) Séries - ( ) Documentários ( ) Música/Musicais - ( ) Variedades - ( ) Infantis - ( ) Animações - (pode marcar mais de uma opção)

11- Como você encontra o que vai assistir? ( ) pesquisa na tela inicial - ( ) pesquisa nos catálogos (filmes/ séries / novidades) - ( ) pesquisa por título(s) - ( ) pesquisa por membros do elenco ( ) pesquisa por diretore(s) - ( )pesquisa por gênero - ( ) cria uma lista de preferidos - ( ) não faz nenhum tipo de pesquisa (pode marcar mais de uma opção, se responder 7, terminar)

12- Ao utilizar as variadas opções de buscas/pesquisas, informadas na pergunta anterior, você encontra o que deseja? ( ) sim - ( ) Não - ( ) nunca realizei buscas.

Qual o grau de facilidade você encontra em cada busca/pesquisa? Use a escala de 1 a 5 , sendo 1 muito fácil e 5 muito difícil.

1( ) 2 ( ) 3 ( ) 4 ( ) 5 ( ) pesquisa na tela inicial

1( ) 2 ( ) 3 ( ) 4 ( ) 5 ( ) pesquisa nos catálogos (filmes/ séries / novidades)

1( ) 2 ( ) 3 ( ) 4 ( ) 5 ( ) pesquisa por título

1( ) 2 ( ) 3 ( ) 4 ( ) 5 ( ) pesquisa por membros do elenco

1( ) 2 ( ) 3 ( ) 4 ( ) 5 ( ) pesquisa por diretore(s)

$1($ ) 2 ( ) 3 ( ) 4 ( ) 5 ( ) pesquisa por gênero

1( ) 2 ( ) 3 ( ) 4 ( ) 5 ( ) cria uma lista de preferidos 
Apêndice B - Questionário final

Declaro que li e estou de acordo com todas as informações apresentadas no termo de consentimento.

( ) Estou de acordo.

( ) Não estou de acordo.

Nacionalidade

$\begin{array}{llllll}1 & - & \text { Você } & \text { é } & \text { brasileiro? } \\ ( & & & \end{array}$

( ) Não

Pesquisa Informação NETFLIX

3 - Qual seu sexo?

\begin{tabular}{lccr}
( & ) & Feminino \\
( ) Masculino & & & dizer \\
( ) Outros: & Prefiro & não & \\
\hline
\end{tabular}

4 - Indique sua faixa etária: *

( ) 18 a 24 anos

( ) 25 a 34 anos

( ) 35 a 44 anos

( ) 45 a 54 anos

( ) 55 a 64 anos

( ) mais de 65 anos

Sobre a NETFLIX 
5 - Há quanto tempo é assinante e/ou usuário Netflix?

( ) Há 2 meses

( ) Entre 3 meses e 8 meses

( ) Há um ano

( ) Mais de um ano

6 - De onde costuma acessar a Netflix? (Pode marcar mais de uma) Marque somente os que utiliza.

( ) Computador/Notebook

( ) Televisão/SmartTV

( ) Tablet

( ) Smartphone (celular)

( ) Videogames

( ) Outras formas de acesso eletrônico

7 - Qual aparelho você prefere utilizar, para acessar a Netflix? (Pode marcar mais de uma) *

Marque somente os que utiliza.

( ) Computador/Notebook

( ) Televisão/SmartTV

( ) Tablet

( ) Smartphone (celular)

( ) Videogames

( ) Outras formas de acesso eletrônico

8 - De acordo com a resposta anterior, caso tenha marcado mais de uma opção: use a escala de 1 a 5 , sendo 1 muito fácil e 5 muito difícil. Qual o grau de facilidade você encontra em cada aparelho eletrônico?

Computador/Notebook

1( ) 2 ( ) $3($ ) 4 ( ) 5 ( )

Televisão Smart TV

1( ) 2 ( ) 3 ( ) 4 ( ) 5 ( )

Tablet

1( ) 2 ( ) $3($ ) $4($ ) $5($ )

Smartphone (celular)

1( ) $2($ ) $3($ ) $4($ ) $5($ )

Videogames

1( )2( ) 3( )4( ) 5( ) 


\section{Preferências}

9 - Ao acessar a Netflix, você: (Pode marcar mais de uma)
( ) Sempre procura o que quer assistir
( ) Assiste ao que é sugerido pelo catálogo
( ) Assiste à indicação feita por amigos
( ) Outros

10 - A que você prefere assistir? (Pode marcar mais de uma)
( ) Filmes
( ) Séries
( ) Documentários
( ) Música/Musicais
() Variedades
() Infantis
( ) Animações

11 - Como você encontra o que vai assistir? (Pode marcar mais de uma)
( ) Pesquisa na tela inicial
( ) Pesquisa nos catálogos (filmes/séries/novidades)
( ) Pesquisa por título(s)
() Pesquisa por membros do elenco
( ) Pesquisa por diretor(es)
( ) Pesquisa por gênero
( ) Cria uma lista de preferidos
( ) Não faz nenhum tipo de pesquisa

12 - Ao fazer a busca, você encontra o que deseja? *
( ) SIM
( ) NÃO
( ) Nunca realizei buscas

Qual o grau de facilidade você encontra em cada busca/pesquisa? Use a escala de 1 a 5 , sendo 1 muito fácil e 5 muito difícil.

Pesquisa na tela inicial

Pesquisa nos catálogos (filmes/ séries / novidades)

1( ) $2($ ) $3($ ) $4($ ) $5($ )

Pesquisa por título

1( ) 2 ( ) $3($ ) $4($ ) $5($ )

Pesquisa por membros do elenco

1( ) 2 ( ) $3($ ) $4($ ) $5($ )

Pesquisa por diretores

1()2( ) $3($ ) $4($ ) $5($ )

Pesquisa por gênero

1()2( ) 3( ) 4( ) 5( )

Cria uma lista de preferidos

1() $2($ ) $3($ ) $4($ ) $5($ )

pesquisa na tela inicial 
Apêndice C - Observação orientada (análise de tarefas): pré-teste e versão aplicada das tarefas

1 - Observar o entrevistado se familiarizar com a plataforma Netflix via notebook.

2 - Busca por conteúdo, via página inicial: Na página inicial do sistema, pedir ao entrevistado que procure, dentre o conteúdo (filme, série etc) ofertado pela Netflix, algo a que assistiria naquele momento.

3 - Busca por séries na barra fixa de temas: Dentro da aba séries, pedir para que o entrevistado faça uma busca por gênero e escolha um conteúdo a que ele gostaria de assistir naquele momento. Obs ${ }^{1}$ : Observar a familiaridade com as ofertas de pesquisa do streaming.

4 - Buscar por filmes na barra fixa de temas: Dentro da aba filmes, pedir para que o entrevistado faça uma busca por gênero e escolha um conteúdo a que ele gostaria de assistir naquele momento. Obs1: Observar a familiaridade com as ofertas de pesquisa do streaming. Obs²: Nesse ponto, mostrar que a Netflix divide sua grade de conteúdo por temas, além de gêneros.

5 - Busca direta 1: Orientar o entrevistado a clicar no desenho da lupa, na página da Netflix. E então fazer uma pesquisa pelo nome de um diretor ou celebridade de que ele goste.

6 - Busca direta 2: Orientar o entrevistado a clicar no desenho da lupa, na página da Netflix. E então fazer uma pesquisa pelo nome de um filme ou série de que ele goste. 